\title{
Comparison of the simplified methods of the ISO 13790 Standard and detailed modelling programs in a regulatory context
}

\author{
Georgios Kokogiannakis ${ }^{\mathrm{a}^{*}}$, Paul Strachan ${ }^{\mathrm{a}}$ and Joe Clarke ${ }^{\mathrm{a}}$ \\ ${ }^{a}$ Energy Systems Research Unit, Department of Mechanical Engineering, University of Strathclyde, Glasgow, UK
}

\begin{abstract}
The CEN Standards that support the European Energy Performance of Buildings Directive requirement for calculation of the energy consumption of buildings allow various methods to be used for the same calculation. The impact of using the different methods within the updated ISO 13790 Standard for space heating and cooling energy calculations was examined with a parametric analysis of a common building specification. The impact was assessed by considering the energy band which would be assigned for the building based on the calculation results. The Standard describes three different methods that can be used for the calculations: a monthly quasi-steady state method, a simplified hourly method and detailed simulation. For most cases studied, differences in the building rating given by the various methods were a maximum of one band. More significant differences were noticed in some cases. Parameter values in the monthly method were determined which would lead to improved matching.
\end{abstract}

Keywords: EPBD, ISO 13790, Simplified Methods, Detailed Simulation Programs

\section{Introduction}

The European Energy Performance of Buildings Directive (EPBD) (EU 2003) requires that Member States should establish a common methodology at national or regional level for the calculation of the integrated energy performance of buildings. To address this requirement, a set of European and International Standards were prepared or updated in order to provide the methods and support material for the calculation. A summary of the most important EPBD Standards is given by Roulet and Anderson (2006); Zweifel (2007) also discusses those Standards and, in particular, those dealing with simulation-related issues.

Various approaches could have been taken with regards to the EPBD energy performance calculation procedures. One option, to allow only a single method for regulation compliance, would have affected design teams who would have to use this single method and developers of existing energy performance calculation programs. If design teams were not familiar with this single calculation method they would have to invest time on learning it and they would be limited to the capabilities of this single method. A compulsory single method would also have implications on the market, and therefore on the development, of existing programs that embed advanced calculation methods. This would possible restrict building designs to the capabilities of the single method and would not encourage the development of innovative technologies outside these capabilities. To avoid these drawbacks, CEN Standards allow the use of a number of methods for the energy performance calculations of buildings and they suggest that particular care should be taken to ensure consistency across them in terms of compliance outputs. Despite the

*Corresponding author. Email: georgios@esru.strath.ac.uk 
significant advantages that this may offer, the fact that there is a range of methods and model types that can be used to evidence compliance for building regulations may lead to substantially different compliance results. This paper investigates this issue. The focus is on space heating and cooling energy requirements because the demand for space heating and cooling is usually the largest component of the overall energy demand in buildings and the associated $\mathrm{CO}_{2}$ emissions are significant compared with the other types of energy demand in buildings (i.e. lighting, domestic hot water, etc.). There is also a significant complexity with regards to these calculations due to the dynamic, non-linear and interactive heat transfer phenomena that should be included in them. Finally, the large number of inputs needed to describe the processes associated with the space heating and cooling energy calculations and the related uncertainty for determining these inputs justify the importance of focusing on the potential calculation methods for space heating and cooling energy requirements.

A framework for the calculation of energy use for space heating and cooling is provided in the updated prEN ISO DIS 13790 Standard (2007), which is one of the main Standards that aim to serve the requirements of the EPBD. Two simplified methods are prescribed within this Standard; a monthly quasisteady state method and a simplified hourly method. The Standard also allows the use of validated detailed simulation programs and gives details for the common procedures and descriptions, boundary conditions and input data that these programs should adopt in order to ensure consistency with the simplified methods. The aim of the 13790 Standard is not to specify the validation procedures and the performance criteria for simulation programs. It states that there are other Standards for this purpose and gives the example of EN 15265 Standard (2007). This paper applies all the methods in this Standard in order to investigate the impact of allowing the use of different methods on energy performance compliance studies. Two detailed simulation programs were used in the study (ESP-r (2007) and EnergyPlus (2006)) to determine the magnitude of differences that may result from the choice of simulation program. These programs were run for compliance calculations according to the procedures prescribed by the Standard. The aim is not to quantify the magnitude of the numerical differences, which may be expected, but to determine whether these methods will lead to different compliance conclusions. It should be noted that the intention is not to assess the accuracy of the methods.

\section{Methodology}

The research considered office buildings as they are a predominant building type where the CEN Standard methods are likely to be applied. The comparison of the various calculation methods when applied to a common building specification was undertaken in terms of the annual energy demand for space heating and cooling.

It is important, however, to determine at this stage the size of the differences from these comparisons that would lead practitioners to obtain different compliance results. A few existing applications classified buildings based on their energy consumption and in some cases there was an additional classification based on the building's energy requirements for space heating. An example is the Italian BESTClass software (2007) which uses different classes with bandwidths between 20 and $30 \mathrm{kWh} / \mathrm{m}^{2}$ per annum difference in their energy consumption to categorise buildings (e.g. classes B, C and D use $20 \mathrm{kWh} / \mathrm{m}^{2}$ per annum and class E uses $30 \mathrm{kWh} / \mathrm{m}^{2}$ per annum). With the introduction of EPBD and its requirement for energy certificates, some countries started adopting software applications that place buildings in different bands based on their energy consumption or, more commonly, on their $\mathrm{CO}_{2}$ emissions output. In Scotland, for example, the outputs from the SBEM program (2008) produce energy certificates that categorise buildings in different bands by directly considering their calculated annual $\mathrm{CO}_{2}$ emissions output. In this case, an office building with electric heating and cooling would be placed in a different band if the calculated space heating and cooling energy requirements vary from 16 to $19 \mathrm{kWh} / \mathrm{m}^{2}$ per annum (i.e. as a consequence of associated high $\mathrm{CO}_{2}$ emissions: for example $17 \mathrm{kWh} / \mathrm{m}^{2}$ per annum defines the range for the $\mathrm{B}+$ band, $19 \mathrm{kWh} / \mathrm{m}^{2}$ per annum for $\mathrm{B}, 16 \mathrm{kWh} / \mathrm{m}^{2}$ per annum for $\mathrm{C}+$, etc.). Based on these examples, and for the purposes of this study, $20 \mathrm{kWh} / \mathrm{m}^{2}$ per annum has been considered a critical benchmark for the 
comparison of the space heating and cooling results produced from the various methods. A similar scale to the one for Scotland is used in this paper for the presentation of the results. Letters will be used together with the "+" symbol for every letter (i.e. A+, A, B+, B, etc.); each adjacent category indicates a difference of $20 \mathrm{kWh} / \mathrm{m}^{2}$ per annum in the space heating and cooling results. This decision may have implications in cases where the numerical results from the different calculation methods are close to each other but fall around a class boundary. It may be possible in these cases that different ratings are assigned from the calculation methods without the occurrence of large numerical differences. The discussion of the results does not consider these cases as critical but they are however representative of possible realistic situations that could also occur with the actual energy performance ratings produced from different calculation methods. Due to the fact that a number of parametric cases in this paper were undertaken for various climate locations, the compliance results should not be directly compared between cases but only between the various calculation methods. One way to overcome this would have been to normalise the results of the various locations based on heating or cooling degree days but this has not been considered important for the purposes of the paper due to the fact that the focus is on the compliance results between the calculation methods. To achieve the objective of this study, it has been considered important to ensure model equivalence for all methods in terms of boundary conditions and inputs used. Details of the case study used for the purposes of the comparison and the way model equivalence has been achieved are given in the following sections.

\subsection{Case study and parametric analysis}

The building used for this case study consisted of 9 spaces of different geometry aligned in a way that considers different possibilities of exposure (i.e. ground/mid/top floor) and façade orientations. The total floor area of the building is $336 \mathrm{~m}^{2}$. Figure 1 shows the simulated base case.

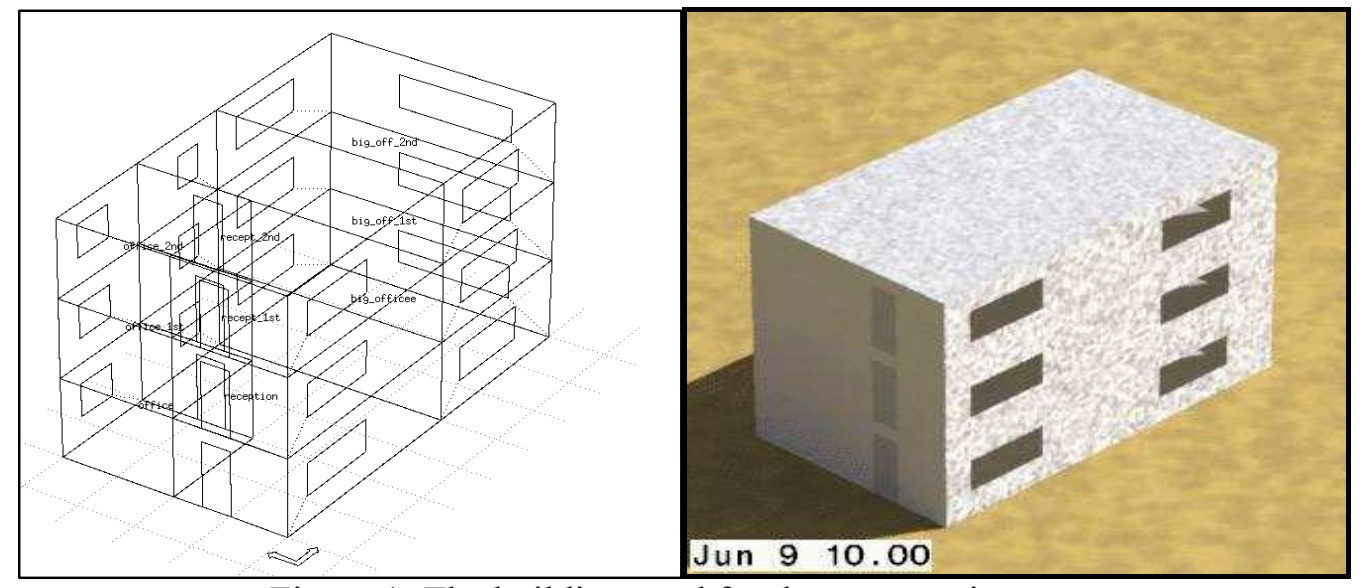

Figure 1: The building used for the parametric cases.

The base case for the annual heating calculation was based on a central/northern European location (Amsterdam). Cooling requirements were determined for the same location. An additional base case for a southern European location (Athens) was used to determine the sensitivity of the methods to higher cooling loads. Alternative locations were also studied for the heating and cooling calculations as part of the climate variations in the parametric study. To avoid increasing the complexity of the calculations with regards to the simplified methods, all spaces were assumed to have the same temperature set-point for heating and cooling and also the same heating, cooling, ventilation and internal gains schedules. This strategy has been adopted because the typical application of the simplified methods ignores the dynamic interactions between the thermal zones and a direct comparison with the dynamic simulation programs would not therefore be fully realistic. Multi-zone coupling for the simplified methods is considered 
possible within the 13790 Standard but the resulting calculations are complex and the Standard does not recommend their application.

The parametric studies covered design parameters that typically will have a significant effect on the building's annual heating and cooling energy requirements. Some parameters did not affect the monthly method (e.g. changing the internal gain profiles) and these were used to assess the impact of assuming average monthly values. Results for the following parameter variations were considered.

- Three building locations and climates, representing a southern, central and northern European location.

- Five internal heat gains schedules. The base case incorporates occupant and lighting schedule where the gains during occupied hours are $12 \mathrm{~W} / \mathrm{m}^{2}$ and $10 \mathrm{~W} / \mathrm{m}^{2}$ respectively and $10 \%$ of these values during unoccupied hours and weekends. Two cases used the same average monthly internal heat gains values as the base case; in one, the values are hourly averages for every day of the week (i.e. the same hourly value at each hour throughout the week); in the other, values are averaged for every hour separately for weekdays and weekends (i.e. a constant hourly value during weekdays with a separate value at weekends). A third case used higher internal heat gain values (compared to the base case) but with the same hourly pattern, while the last case used lower values, again with the same hourly pattern as the base case.

- Three glazing areas: the base case using $58 \mathrm{~m}^{2}$ and two other cases using half and double this amount.

- Four external wall constructions, corresponding to ultra-lightweight, lightweight and heavyweight cases with standard insulation, and a low insulation heavyweight case.

- Five ventilation schedules. The base case model assumed a constant ventilation rate of $0.72 \mathrm{ac} / \mathrm{h}$ throughout the year; two cases used higher $(1.5 \mathrm{ac} / \mathrm{h})$ and lower $(0.3 \mathrm{ac} / \mathrm{h})$ constant ventilation rates; and two cases used the same average monthly ventilation rates as the base case but varied the magnitude throughout each day to reflect occupancy.

- Three building orientations: the base case was rotated $90^{\circ}$ and $180^{\circ}$ anticlockwise.

- Six heating and cooling set-point strategies. Three of these strategies have a steady temperature setpoint throughout the year and three have intermittent heating/cooling.

\subsection{Model equivalencing}

While it has not been explicitly stated in the 13790 Standard, the procedures suggested for the application of all methods in practice for a common purpose (e.g. for regulation compliance checks) may constrain detailed simulation programs to use less advanced procedures than they normally use in order to match the inputs and boundary conditions used in the simplified methods. This section will follow these procedures in order to allow comparisons to be made between the results of all four methods. Input data and boundary condition equivalencing between the methods was ensured as follows.

The same climate files were used for both ESP-r and EnergyPlus (Crawley et al 1999). Tabulated hourly temperature data were then exported and used with the simplified methods (after averaging in the case of the monthly method). With solar radiation data, the incident solar radiation on all surfaces was calculated by the simulation programs and used as inputs to the simplified methods.

The set-point temperatures, even in the cases of intermittency, were the same for all methods. In ESP-r, ideal controls were used to maintain the operative temperature in the zones at the value set in the simplified methods, while in EnergyPlus an ideal system ('Purchased Air') was employed to the same end. With intermittent operation, the method described in the 13790 Standard for the simplified monthly method was used to determine the relevant reduction factors.

In relation to fabric conduction, the same areas, materials, layers and constructions of the building were used in all methods. In order to set the same surface resistances, the pre-defined values given in prEN ISO 
DIS 6946 (2006) (and prEN ISO DIS 10077-1 (2006) in the case of windows) were used. This means that for ESP-r and EnergyPlus, the inside and outside convective and radiative heat transfer coefficients were held constant throughout simulations (i.e. because the simplified methods use fixed surface resistances). Regarding the heat transmission to the ground, the method described in Annex D of the prEN ISO DIS 13370 (2006) was used with the detailed simulation programs to model the construction of the floor and the boundary condition below it. This included a specific thickness of soil and a virtual layer with specific thermophysical properties below it. The resulting calculated monthly ground temperatures were used over the simulation period. Regarding the simplified methods, heat transfer coefficients were used in accordance with the 13790 and related Standards (i.e. the 13789 Standard (2007), which points to the 13370 Standard). Thermal bridges were not accounted for in any of the methods. For the foundation, a slab on the ground was assumed with 1-D thermal conduction only.

Equivalency between the input data for all methods with regards to the losses from ventilation or infiltration was ensured by using the same air flow schedules on an hourly and monthly basis. However, ventilation heat losses or gains are based on the operative temperature in the monthly simplified method and on the air temperature in the simplified hourly and the detailed simulation programs, but because this is not an input or a boundary condition difference the equivalency between the methods is maintained. The air is assumed to be supplied from the external environment to building spaces at the ambient temperature. The internal heat capacities of the building constructions were represented explicitly in the detailed programs and via the use of an internal heat capacity factor, $C_{m}$, according to the 13790 Standard in the simplified monthly and hourly methods.

For solar gains, equivalency between the 13790 methods was ensured by following the given rules. Specialised programs, WIS (2004) and WINDOW 5.2 (2005), were used to provide detailed optical properties for the detailed simulation programs and the solar energy transmittance (g-value) for the simplified methods. Window frames were not taken into account by any of the calculation methods and no shading devices were applied.

The external surface emissivities were set to zero in order to impose a fixed surface resistance on the detailed simulation programs. This means that the longwave radiation heat exchange with the sky was not taken into account. Detailed simulation programs solve the heat transfer by transmission and radiation to the sky simultaneously, so they cannot follow at the same time both of the ISO 13790 instructions for their treatment. It is not possible, in other words, to model the transmission losses assuming a fixed radiative heat transfer coefficient and, at the same time, use a time varying external radiative heat transfer coefficient for the longwave radiation heat exchange with the sky. For purposes of equivalency between all the methods, the longwave radiation heat exchange with the sky was not taken into account in any of the calculation methods.

The internal heat gains in the spaces were the same for every method. The same schedules were used on an hourly or monthly basis. In ESP-r and EnergyPlus, a 50\% convective and 50\% radiative fraction was assumed in accordance with the ISO 13790 instructions.

\section{Results and discussion}

Results are presented in terms of rating outputs from the various calculation methods. The full set of numerical results of the different calculation methods for the building's annual heating and cooling energy requirements are also given for reference in Tables 1 and 2 respectively. All cases studied in this paper are given a "case ID" number for making easier their discussion and display in graphs. This "case ID" number can be found in Tables 1 and 2.

Of the twenty-three cases for heating, six cases (case ID: 3, 7, 9, 11, 16 and 19) produced results that, although they are not numerically the same between the different methods used, they are within the same rating bands. Of the remaining seventeen cases the results of the four calculation methods did not differ more than one band (i.e. considering the lower limit of a band and the upper limit of the next band: less than $40 \mathrm{kWh} / \mathrm{m}^{2}$ annum), as is shown in Figures 2 and 3. 
With the exception of the case where insulated heavyweight walls were used and the cases of intermittent heating, it can be seen that there is a general trend for the monthly method of the 13790 Standard to produce results that place the building at a slightly worse rating band than the other methods. For the intermittent heating cases (i.e. case ID: 21, 22 and 23), the simplified methods seem to favour better rating bands than the simulation programs. It can also be noticed from the results of intermittent heating cases that there is often a lack of sensitivity of the monthly method to the variations in the daily set-point schedules (see case ID: 21 and 22).

For a small number of cooling cases, all four calculation methods produced the same rating results. For only six cases out of the forty-three cooling cases the results were placed within the same band for all calculation methods (case ID: 11, 21, 30, 34, 37 and 41). Of the remaining thirty-seven cases, the results did not differ by more than one band apart from six cases where different bands were produced by the different methods. Details of these thirty-seven cases can be obtained from Tables 1 and 2. The six cases for which there was more than one band difference between the four calculation methods are shown in Figure 4. Of these six cases, three were for the Amsterdam climate: a case where the internal heat gains do not vary through the day (case ID: 4), a case where the internal heat gains vary only between weekdays and weekends (case ID: 5) and a case for which high internal gains were assumed (case ID: 6). The last of these may be particularly common, considering the high use of office equipment often found in this type of building. The other three of the six cases that produced large disagreements in the cooling rating results were for the Athens climate: the case where the building was assumed to be highly glazed (i.e. case ID: 28 , doubling the size of the windows for the base case) and the cases of intermittent cooling during the night (case ID: 42) and during different periods over the day (case ID: 43).

It can be seen from Figure 4 that in all six cases the monthly method produces results that place the building at a slightly worse rating than the other methods. In the case of night cooling (i.e. case ID 42 in Figure 4), however, the monthly method places the building in a band which is three (or almost four) ratings worse than the band given by the simplified hourly method. The results of the two simulation programs for this case differ from both of the two simplified methods; although numerically they are only slightly different from each other, the difference is close to the limits of a band and a different rating is produced from them (i.e. B+ with ESP-r and B with EnergyPlus).

The intermittent cooling results produced confirmed the expected lack of sensitivity of the monthly method to the variations in the daily set-point schedules (see case ID: 21, 22, 23, 41, 42 and 43 in Table 2). As a general conclusion from the cooling cases for which differences in the compliance results were noticed and from all the numerical results produced for the cooling cases in this paper, it can be stated that there is a trend for the monthly method to produce results that place the building at a worse rating than the other methods. The next section will investigate possible ways to overcome this inconsistency and will discuss how the monthly method could be optimised and produce outputs closer to the other methods.

\section{Optimising the monthly method of the 13790 Standard}

This section investigates the possibility of optimising the monthly method in order to bring the compliance results produced from this method closer to the results of the other methods.

To identify the critical factors that could be optimised for this method, the outputs of the calculated gains and losses from the simulation programs and the monthly method for the base case building were compared. The simplified hourly method was excluded from this comparison because there is no way to determine separately the heat losses from this method. The comparison confirmed that heat gains (solar and internal) and heat losses (ventilation and fabric conduction) were similar between the methods when the instructions of the 13790 Standard were followed. This also confirmed that the equivalencing procedures described earlier in this paper were successfully applied. It was therefore concluded that the calculation of the utilisation factor used in the monthly method to account for dynamic effects had a major potential for being optimised. (The utilisation factor, for example for the heating calculations, attempts to account for the "useful" part of the internal and solar heat gains during the heating period, and is 
influenced largely by the thermal mass at the internal surfaces.) This possibility will be further discussed in this section.

A complete description of the monthly method would not be possible here due to the size of the 13790 Standard. However, the basic equations involved in the calculation of the utilisation factor are described briefly here:

The gain-loss ratio for heating $\left(\gamma_{H}\right)$ and cooling $\left(\gamma_{C}\right)$ are quantified as a first step based on monthly heat gains $\left(Q_{H_{-} \text {gains }}, Q_{C_{-} \text {gains }}\right)$ and losses $\left(Q_{H_{-} \text {losses }}, Q_{C_{-} \text {losses }}\right)$ for heating and cooling respectively. This is summarised in equation 1 (the calculation for $\gamma_{H}$ is separate from the calculation of $\gamma_{C}$ but the symbol $\gamma_{H, C}$ is used in the following equations to define both of them when common rules apply).

$$
\begin{array}{ccc} 
& \gamma_{H}=\frac{Q_{H_{-} \text {gains }}}{Q_{H_{-} \text {losses }}} & \gamma_{C}=\frac{Q_{C_{-} \text {gains }}}{Q_{C_{-} \text {losses }}} \\
\text { if } \gamma_{H, C} \geq 0 \text { and } \gamma_{H, C} \neq 1: & \eta_{H, g n}=\frac{1-\gamma_{H}^{a_{H}}}{1-\gamma_{H}^{a_{H}+1}} & \eta_{C, \text { loss }}=\frac{1-\gamma_{C}{ }^{-a_{C}}}{1-\gamma_{C}{ }^{-\left(a_{C}+1\right)}} \\
\text { if } \gamma_{H, C}=1: & \eta_{H, g n}=\frac{a_{H}}{a_{H}+1} & \eta_{C, \text { loss }}=\frac{a_{C}}{a_{C}+1} \\
\text { if } \gamma_{H, C}<0: & \eta_{H, g n}=\frac{1}{\gamma_{H}} & \eta_{C, \text { loss }}=1
\end{array}
$$

where,

$\eta_{H, g n}$ and $\eta_{C, \text { loss }}$ are the utilisation factors for heating and cooling respectively.

$a_{H}$ and $a_{C}$ are dimensionless reference numerical parameters for heating and cooling respectively and are described by equation (5). The symbol $\alpha_{H, C}$ is used here to define both of them but they are calculated separately.

$$
\alpha_{H, C}=\alpha_{0_{H, C}}+\frac{\tau}{\tau_{0_{H, C}}}
$$

where $\alpha_{0_{H, C}}$ is defined in the 13790 Standard as the reference dimensionless numerical parameter with a suggested default value of 1 for both heating and cooling, $\tau$ is the building time constant and $\tau_{0_{H, C}}$ is defined as the reference time constant with a suggested default value of 15 hours for both heating and cooling.

The following paragraphs identify the most appropriate reference numerical parameters for improving the inter-method match of the rating results produced in this paper, without changing the utilisation factor main equations (i.e. equations 1 to 4$)$. The objective here is to identify the best combination of $\left(\alpha_{0_{H, C}}\right)$ and $\left(\tau_{0_{H, C}}\right)$. 
To this end, the correlation developed by Corrado and Fabrizio (2007) is also used with the monthly method whereby the numerical parameter $\left(\alpha_{C}\right)$ that is used in the calculation of the utilisation factor for cooling is instead described by:

$$
\alpha_{C}=8.1-13 \xi+\frac{\tau}{17}
$$

where $\xi$ is the window-to-floor area ratio. Although this correlation aims to improve the results of the monthly method for the calculation of the cooling energy requirements, its effect on the results for heating was also investigated.

\subsection{Optimisation results}

An iterative investigation revealed the best combination of the two numerical parameters to be $\alpha_{0}=3.5$ and $\tau_{0}=10$ hours. Imposing these values on the simplified monthly method produced results that were placing the building in bands closer to the other methods and especially to results of the simulation programs. Thirteen cases out of the twenty-three heating cases and twenty-two out of the forty-three cooling cases produced exactly the same rating when the new numerical parameters were used in the monthly method. In almost all of the remaining cases for heating and cooling, there is only one band difference in the rating results and this is often associated with small numerical differences that are close to the limit values of a band. Similar trends were noticed when the correlation of Corrado and Fabrizio was used, for which in almost all cases slightly lower numerical results were produced compared to the results of the monthly method with the optimised numerical parameters (i.e. $\alpha_{0}=3.5$ and $\tau_{0}=10$ hours). The largest differences for the heating results after the optimisation of the monthly method were noticed again for the cases of intermittent heating (case ID 21, 22 and 23). The intermittent cooling cases during the night and at different periods during the day for the warm climate (i.e. case ID: 42 and 43) are still generating the largest differences between the rating results of the various methods. For these two intermittent cooling cases, the correlation of Corrado and Fabrizio seems to be the best alternative for use in the monthly method. Figures 5 and 6 show some examples of the rating results after the application of the improvements in the monthly method. These examples were based on some of the cases of Figures 2 to 4 where differences in the initial rating results before the optimisation were noticed. They include the five cases for intermittent heating and cooling and some additional examples for which the improvements on the monthly method were notable.

While the optimisation process of the monthly method improved the rating results, further research is needed on the impact of the use of the various methods on different building types and especially where advanced building design techniques are used (e.g. atriums, double ventilated facades, etc.). Large differences may be produced in such cases and the choice of a calculation method should be based on validation procedures and guidance from the policy makers of the countries that are adopting these methods (e.g. detailed guidance on the applicability and the limitations of the potential methods). An example of such a case where large differences in the cooling results were noticed for an office building incorporating a mechanically ventilated double façade is given by Kokogiannakis and Strachan (2007).

\section{Conclusions}

While prescribing calculation methods within the EPBD offers advantages, it also raises the issue of method conformity in a regulatory context. To investigate this issue the methods described within the 13790 CEN Standard were applied to a common building specification and the space heating and cooling predictions compared. Building model and boundary condition equivalence was attained by adhering to instructions contained in the Standard, which necessitated assumptions that are not consistent with those used in practice. 
The results from the study show that, in terms of space heating, all methods would place the building either within the same or an adjacent band. The largest differences were noted for the case of intermittent heating.

With space cooling, there were a small number of cases where the results from each method were within the same band. The majority, however, were rated differently by the methods: of these the majority were within a single band range, while six cases exhibited large differences, the most notable corresponding to night cooling in a warm climate.

Overall the results indicate that apart from the intermittent heating cases, there is a general trend concerning the monthly method, whose predictions are higher than the other methods, resulting in many cases in a different rating. Alternative numerical parameters and modelling assumptions were demonstrated to bring the results for this method in line with the other methods, although differences for the case of night cooling in a warm climate were still significant. Unfortunately, the alternative assumptions are not applicable to every building design and especially for cases that use advanced technologies.

This study has demonstrated that while the choice of methods allowable under the CEN Standard will have an impact on the produced ratings, this impact will in most cases be small. While valid for office buildings, as studied, this conclusion is not applicable to other building types. Method application guidance should be provided for all building types to avoid inconsistent and inappropriate performance ratings.

\section{References}

BESTClass Software, 2007. Polytechnic of Milan and Province of Milan, Italy. Available from: http://www.sacert.eu/bestclass.php

Corrado V and Fabrizio E, 2007. Assessment of Building Cooling Energy Need through a Quasi-steady State Model: Simplified Correlation for Gain-loss Mismatch. Energy and Buildings, 39 (5), 569579.

Crawley DB, Hand JW, and Lawrie LK, 1999. Improving the Weather Information Available to Simulation Programs. Proceedings Building Simulation '99, Kyoto, Japan.

EN 15265, 2007. Thermal Performance of Buildings - Calculation Methods of Energy Use for Space Heating and Cooling - General Criteria and Validation Procedures. Brussels, Belgium.

EN ISO 13789, 2007. Thermal Performance of Buildings - Transmission and Ventilation Heat Transfer Coefficient - Calculation Method. ISO, Geneva.

EnergyPlus 1.4.0.025, 2006. Building Energy Simulation Program. Available from: http://www.energyplus.gov.

ESP-r 10.14, 2007. Building Energy Simulation Program. University of Strathclyde, Glasgow, UK. Available from: http://www.esru.strath.ac.uk.

EU, 2003. Directive 2002/91/EC of the European Parliaments and of the Council of 16 December 2002 on the Energy Performance of Buildings. Official J. of the European Communities (L1).

Kokogiannakis G and Strachan P, 2007. Modelling of Double Ventilated Facades According to CEN Standard 13790 Method and Detailed Simulation, Proceedings 2nd PALENC Conference and 28th AIVC Conference, Crete, Greece.

prEN ISO DIS 10077-1, 2006. Thermal Performance of Windows, Doors and Shutters - Calculation of Transmittance - Part 1: General. ISO, Geneva.

prEN ISO DIS 13370, 2006. Thermal Performance of Buildings - Heat Transfer via the Ground Calculation Methods. ISO, Geneva.

prEN ISO DIS 13790, 2007. Energy Performance of Buildings - Calculation of Energy Use for Space Heating and Cooling. ISO, Geneva. 
prEN ISO DIS 6946, 2006. Building Components and Building Elements - Thermal Resistance and Thermal Transmittance - Calculation Method. ISO, Geneva.

Roulet, C.A. and Anderson, B., 2006. CEN Standards for implementing the European Directive on Energy Performance of Buildings. Proceedings 23rd International Conference on Passive and Low Energy Architecture, Geneva, Switzerland.

SBEM v3.1, 2008. Simplified Building Energy Model. BRE, UK. Available from: http://www.ncm.bre.co.uk/

WIS, 2004. Window Information System. WinDat European Thematic Network. Available from: http://windat.ucd.ie/wis/html/index.html.

WINDOW5.2, 2005. Lawrence Berkeley National Laboratory, USA. Available from: http://windows.lbl.gov/software/

Zweifel, G., 2007. New EPBD related European Standards and their relation to building and HVAC system simulation. Proceedings Building Simulation ’07, Beijing, China.



Figure 2. Cases between 1 and 13 where differences in the ratings for annual space heating energy requirements $\left(\mathrm{kWh} / \mathrm{m}^{2}\right.$ annum) were noticed 


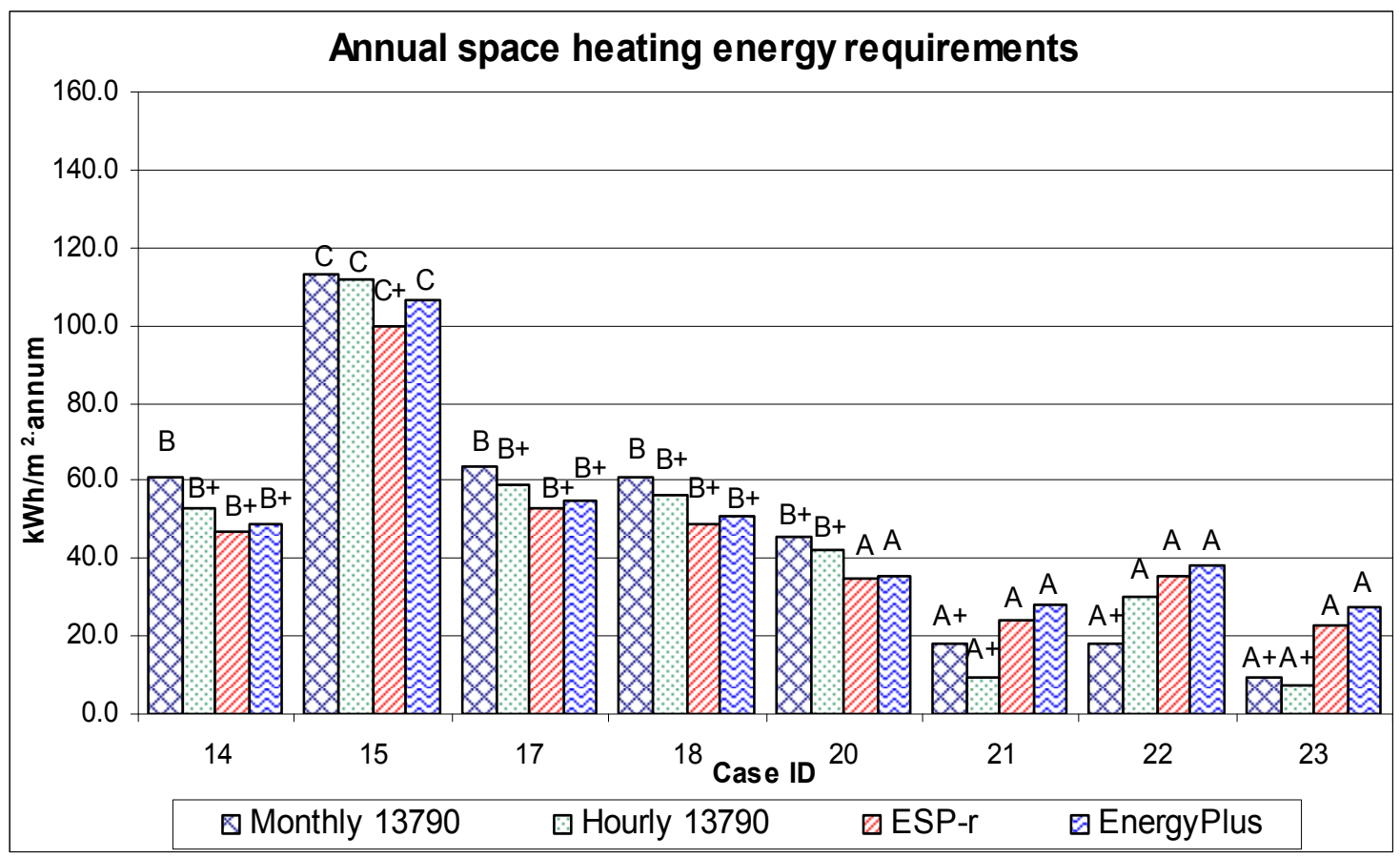

Figure 3. Cases between 14 and 23 where differences in the ratings for annual space heating energy requirements $\left(\mathrm{kWh} / \mathrm{m}^{2}\right.$ annum) were noticed

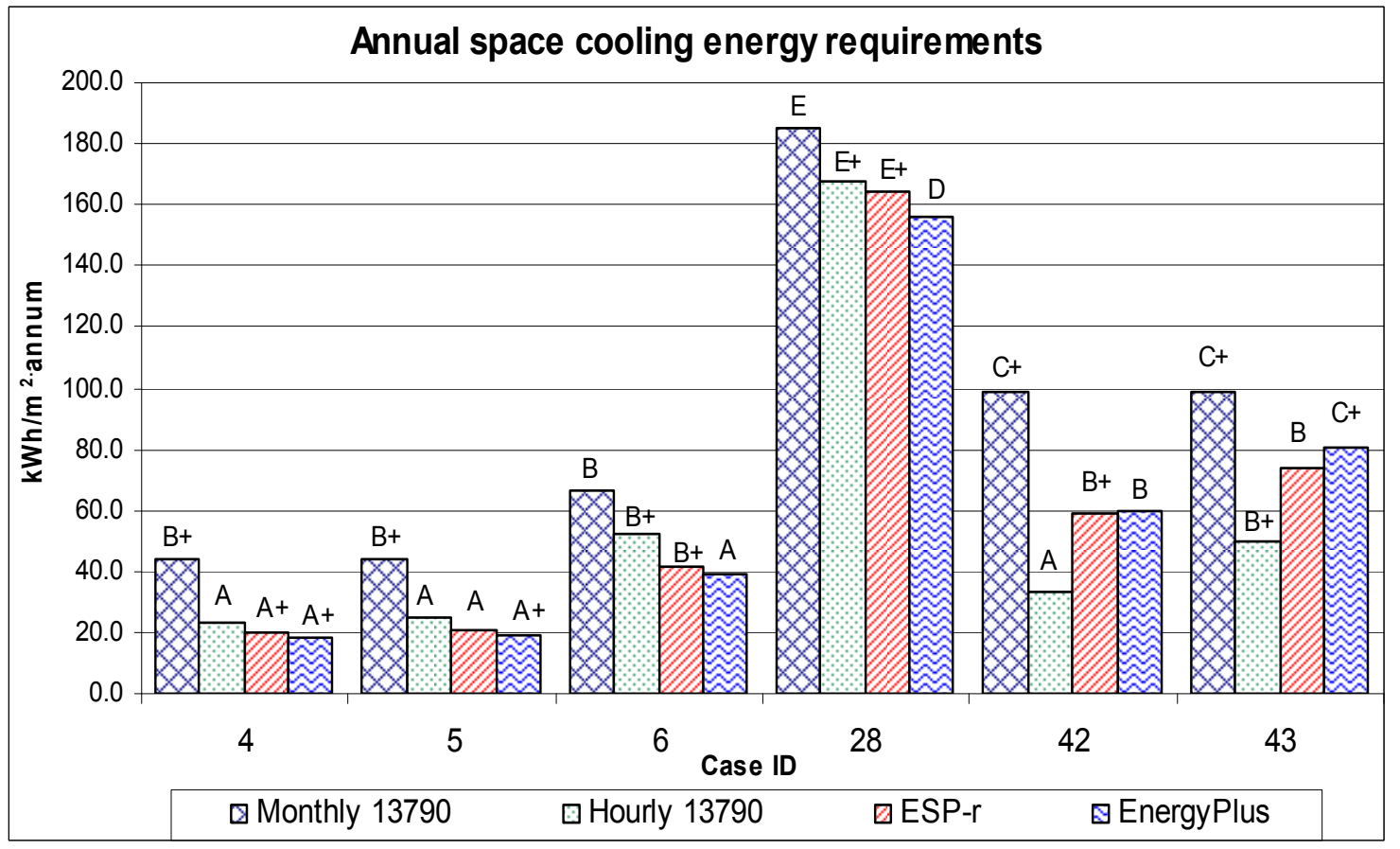

Figure 4. Characteristic differences in ratings for annual space cooling energy requirements $\left(\mathrm{kWh} / \mathrm{m}^{2}\right.$ annum) 


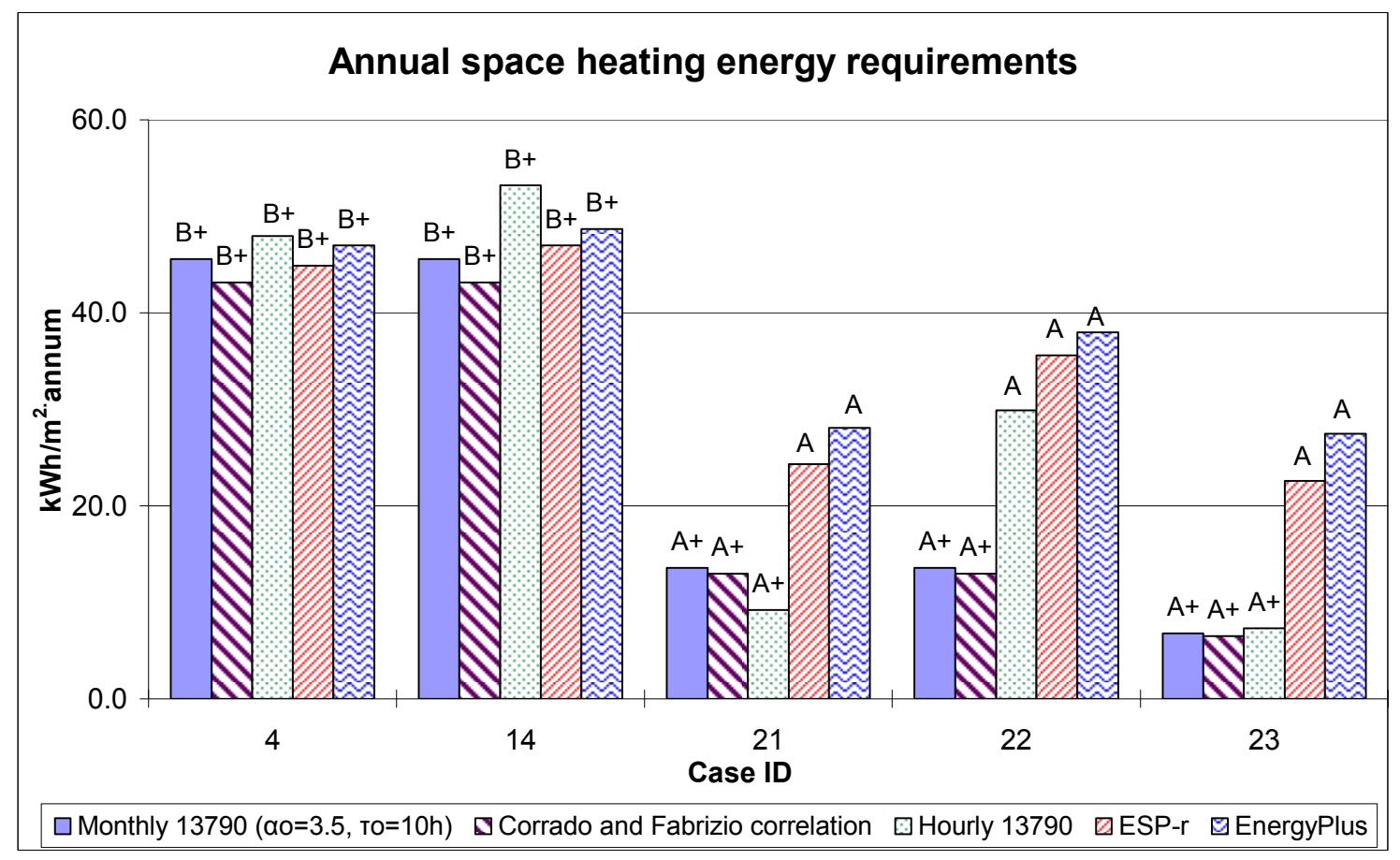

Figure 5. Optimisation: annual space heating energy requirements $\left(\mathrm{kWh} / \mathrm{m}^{2}\right.$ annum).

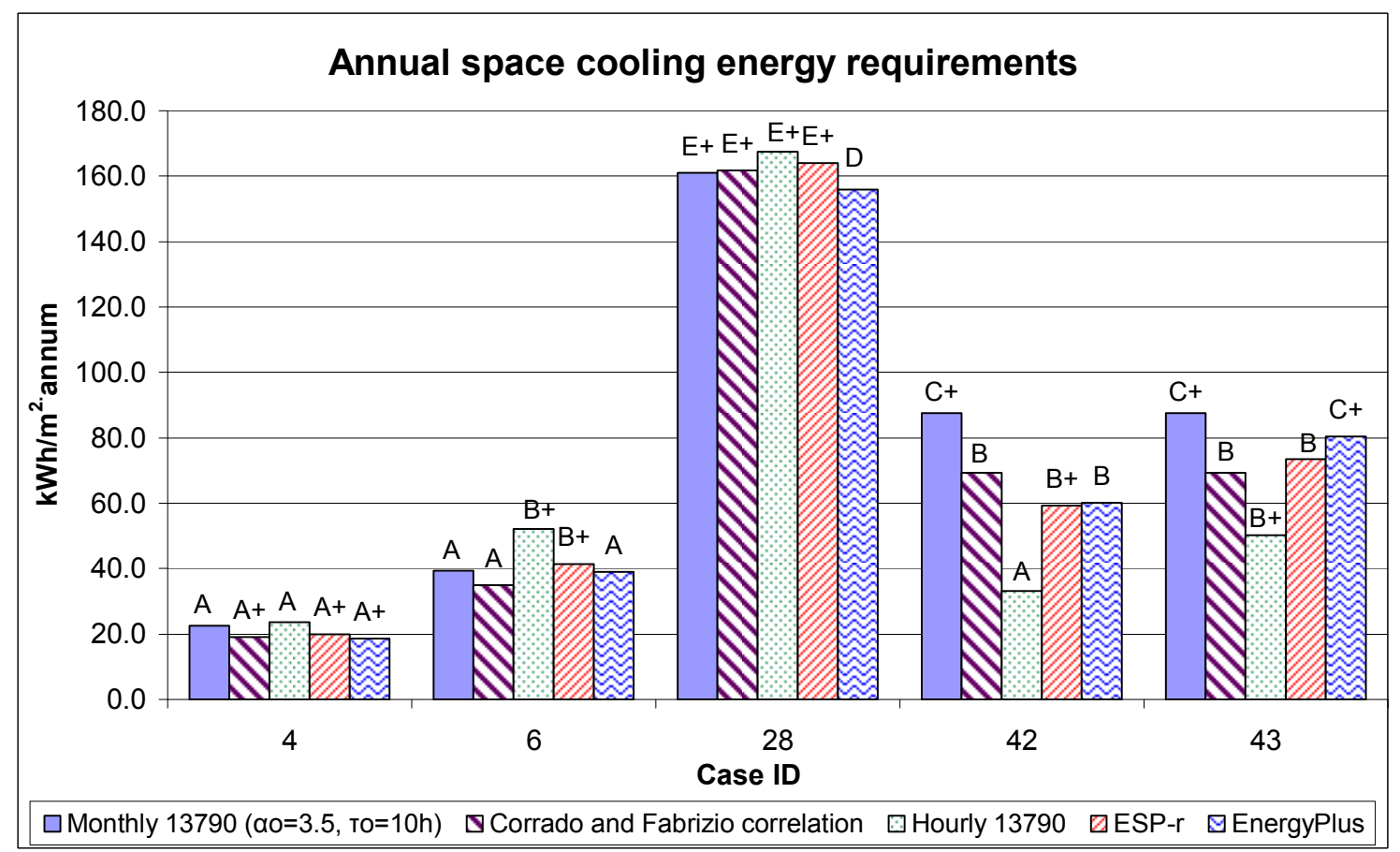

Figure 6. Optimisation: annual space cooling energy requirements $\left(\mathrm{kWh} / \mathrm{m}^{2}\right.$ annum). 
Table 1. Annual heating energy requirements ( $\mathrm{kWh} / \mathrm{m}^{2}$.annum)

\begin{tabular}{|c|c|c|c|c|c|}
\hline $\begin{array}{l}\text { Case } \\
\text { ID }\end{array}$ & Description & $\begin{array}{c}\text { Monthly } \\
13790\end{array}$ & $\begin{array}{c}\text { Hourly } \\
13790\end{array}$ & EnergyPlus & ESP-r \\
\hline 1 & Base Case (Amsterdam $-19^{\circ} \mathrm{C}$ set-point) & 61.1 & 56.1 & 50.3 & 46.3 \\
\hline 2 & Climate Aberdeen & 73.7 & 66.5 & 58.2 & 53.8 \\
\hline 3 & Climate Athens & 14.0 & 12.0 & 5.2 & 4.6 \\
\hline 4 & Internal Gains averaged hourly (7 days/week) & 61.1 & 48.0 & 47.0 & 44.9 \\
\hline 5 & Int. Gains averaged hourly (Weekdays/Weekends) & 61.1 & 49.2 & 47.9 & 45.8 \\
\hline 6 & High internal gains & 50.7 & 44.0 & 35.1 & 31.5 \\
\hline 7 & Low internal gains & 76.6 & 74.7 & 71.7 & 67.0 \\
\hline 8 & Glazing area: double & 77.9 & 70.8 & 63.9 & 56.5 \\
\hline 9 & Glazing area: half & 53.2 & 49.8 & 44.9 & 42.8 \\
\hline 10 & Construction: ultra-lightweight $\left(C_{m}=56.9 \mathrm{~kJ} / \mathrm{m}^{2} \mathrm{~K}\right)$ & 68.3 & 63.3 & 57.1 & 55.4 \\
\hline 11 & Construction: heavyweight $\left(C_{m}=231.6 \mathrm{~kJ} / \mathrm{m}^{2} \mathrm{~K}\right)$ & 47.2 & 46.7 & 47.4 & 45.4 \\
\hline 12 & Construction: heavyweight, no insulation & 138.0 & 125.0 & 141.8 & 142.0 \\
\hline 13 & Ventilation daily schedule & 61.1 & 52.9 & 48.5 & 46.8 \\
\hline 14 & Ventilation Weekday/Weekends schedule & 61.1 & 53.2 & 48.7 & 47.0 \\
\hline 15 & High ventilation rates $(1.5 \mathrm{ac} / \mathrm{h})$ & 113.4 & 111.5 & 106.5 & 99.7 \\
\hline 16 & Low ventilation rates $(0.3 \mathrm{ac} / \mathrm{h})$ & 35.3 & 29.8 & 23.8 & 23.9 \\
\hline 17 & Rotate $90^{\circ}$ anticlockwise & 63.9 & 58.7 & 55.1 & 53.0 \\
\hline 18 & Rotate $180^{\circ}$ anticlockwise & 60.8 & 56.1 & 50.6 & 48.8 \\
\hline 19 & 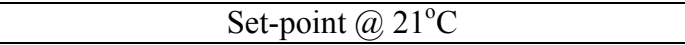 & 79.5 & 73.0 & 67.1 & 64.6 \\
\hline 20 & Set-point@17 $17^{\circ} \mathrm{C}$ & 45.3 & 42.5 & 35.8 & 34.5 \\
\hline 21 & Intermittent heating $7-17.00 \mathrm{~h}$ & 18.2 & 9.2 & 28.1 & 24.3 \\
\hline 22 & Intermittent heating $0-10.00 \mathrm{~h}$ & 18.2 & 29.9 & 38.0 & 35.6 \\
\hline 23 & Intermittent heating (different periods @ 19 $\mathrm{C}$ ) & 9.1 & 7.3 & 27.5 & 22.6 \\
\hline
\end{tabular}


Table 2. Annual cooling energy requirements ( $\mathrm{kWh} / \mathrm{m}^{2}$. annum)

\begin{tabular}{|c|c|c|c|c|c|}
\hline $\begin{array}{c}\text { Case } \\
\text { ID }\end{array}$ & Description & $\begin{array}{c}\text { Monthly } \\
13790\end{array}$ & $\begin{array}{c}\text { Hourly } \\
13790\end{array}$ & EnergyPlus & ESP-r \\
\hline 1 & Base Case (Amsterdam - $24^{\circ} \mathrm{C}$ set-point) & 43.8 & 32.0 & 22.3 & 24.1 \\
\hline 2 & Climate Aberdeen & 34.3 & 18.6 & 9.3 & 10.6 \\
\hline 3 & Climate Athens & 116.3 & 106.1 & 98.2 & 100.2 \\
\hline 4 & Internal Gains averaged hourly (7 days/week) & 43.8 & 23.5 & 18.6 & 20.0 \\
\hline 5 & Int. Gains averaged hourly (Weekdays/Weekends) & 43.8 & 24.6 & 19.2 & 20.6 \\
\hline 6 & High Internal Gains & 66.4 & 52.1 & 39.0 & 41.4 \\
\hline 7 & Low Internal Gains & 23.5 & 16.4 & 9.7 & 10.9 \\
\hline 8 & Glazing area: double & 75.3 & 58.8 & 42.0 & 40.7 \\
\hline 9 & Glazing area: half & 29.0 & 19.9 & 13.0 & 14.0 \\
\hline 10 & Construction: ultra-lightweight $\left(C_{m}=56.9 \mathrm{~kJ} / \mathrm{m}^{2} \mathrm{~K}\right)$ & 43.9 & 31.8 & 22.1 & 24.0 \\
\hline 11 & Construction: heavyweight $\left(C_{m}=231.56 \mathrm{~kJ} / \mathrm{m}^{2} \mathrm{~K}\right)$ & 27.0 & 20.9 & 20.5 & 22.1 \\
\hline 12 & Construction: heavyweight, no insulation & 27.3 & 15.8 & 12.9 & 13.9 \\
\hline 13 & Ventilation daily schedule & 43.8 & 30.0 & 22.4 & 24.1 \\
\hline 14 & Ventilation Weekday/Weekends schedule & 43.8 & 29.9 & 26.2 & 23.8 \\
\hline 15 & High ventilation rates $(1.5 \mathrm{ac} / \mathrm{h})$ & 35.5 & 22.5 & 13.3 & 14.8 \\
\hline 16 & Low ventilation rates $(0.3 \mathrm{ac} / \mathrm{h})$ & 51.2 & 41.6 & 32.0 & 33.7 \\
\hline 17 & Rotate $90^{\circ}$ anticlockwise & 42.5 & 29.9 & 22.0 & 23.6 \\
\hline 18 & Rotate $180^{\circ}$ anticlockwise & 45.4 & 32.0 & 22.5 & 24.3 \\
\hline 19 & 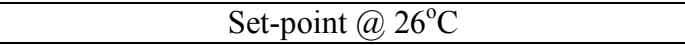 & 37.8 & 24.2 & 14.3 & 15.9 \\
\hline 20 & Set-point @22 ${ }^{\circ} \mathrm{C}$ & 51.4 & 41.4 & 32.2 & 34.2 \\
\hline 21 & Intermittent heating $7-17.00 \mathrm{~h}$ & 31.3 & 28.3 & 20.7 & 21.7 \\
\hline 22 & Intermittent cooling $0-10.00 \mathrm{~h}$ & 31.3 & 6.1 & 9.1 & 9.4 \\
\hline \multirow[t]{2}{*}{23} & Intermittent cooling (different periods @ $24^{\circ} \mathrm{C}$ ) & 31.3 & 17.1 & 19.7 & 18.4 \\
\hline & Base Case (Athens $-24^{\circ} \mathrm{C}$ set-point) & 116.3 & 106.1 & 98.2 & 100.2 \\
\hline 24 & Internal Gains averaged hourly (7 days/week) & 116.3 & 97.4 & 94.6 & 96.1 \\
\hline 25 & Int. Gains averaged hourly (Weekdays/Weekends) & 116.3 & 98.2 & 94.9 & 96.4 \\
\hline 26 & High Internal Gains & 148.1 & 137.6 & 129.5 & 132.3 \\
\hline 27 & Low Internal Gains & 82.3 & 76.3 & 70.3 & 71.7 \\
\hline 28 & Glazing area: double & 184.7 & 167.5 & 155.9 & 164.1 \\
\hline 29 & Glazing area: half & 82.8 & 75.2 & 69.6 & 70.5 \\
\hline 30 & Construction: ultra-lightweight $\left(C_{m}=56.9 \mathrm{~kJ} / \mathrm{m}^{2} \mathrm{~K}\right)$ & 117.1 & 107.5 & 100.4 & 102.6 \\
\hline 31 & Construction: heavyweight $\left(C_{m}=231.56 \mathrm{~kJ} / \mathrm{m}^{2} \mathrm{~K}\right)$ & 103.1 & 93.6 & 97.9 & 99.5 \\
\hline 32 & Construction: heavyweight, no insulation & 128.5 & 107.3 & 120.9 & 123.2 \\
\hline 33 & Ventilation daily schedule & 116.3 & 105.5 & 99.8 & 101.6 \\
\hline 34 & Ventilation Weekday/Weekends schedule & 116.3 & 104.9 & 101.6 & 100.8 \\
\hline 35 & High ventilation rates $(1.5 \mathrm{ac} / \mathrm{h})$ & 112.6 & 101.3 & 94.0 & 95.4 \\
\hline 36 & Low ventilation rates $(0.3 \mathrm{ac} / \mathrm{h})$ & 120.7 & 112.3 & 106.1 & 108.1 \\
\hline 37 & Rotate $90^{\circ}$ anticlockwise & 117.6 & 104.4 & 101.2 & 102.5 \\
\hline 38 & Rotate $180^{\circ}$ anticlockwise & 118.8 & 104.0 & 96.4 & 98.4 \\
\hline 39 & 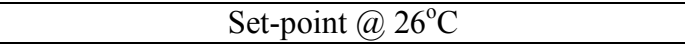 & 99.9 & 89.2 & 79.6 & 81.5 \\
\hline 40 & Set-point@22 $@ 2^{\circ} \mathrm{C}$ & 133.7 & 125.6 & 119.1 & 121.2 \\
\hline 41 & Intermittent cooling $7-17.00 \mathrm{~h}$ & 99.0 & 80.4 & 84.0 & 84.3 \\
\hline 42 & Intermittent cooling $0-10.00 \mathrm{~h}$ & 99.0 & 33.1 & 60.1 & 59.3 \\
\hline 43 & Intermittent cooling (different periods @ 24 $4^{\circ} \mathrm{C}$ ) & 99.0 & 50.2 & 80.4 & 73.5 \\
\hline
\end{tabular}

